\title{
MJN \\ SEXUALLY ACTIVE COLLEGE STUDENTS': KNOWLEDGEABLE ON SEXUALLY TRANSMITTED INFECTIONS BUT WHY THEY ARE RISKING IT WITH THEIR SEXUAL BEHAVIORS?
}

\author{
Minnie B. Mamauag*, Zeth Jehann A. Fortich, Kate F. Logronio, Jessa May R. Mongado \\ College of Nursing, MSU-Iligan Institute of Technology, Philippines \\ *Corresponding Author's Email:minnie.mamauag@g.msuiit.edu.ph
}

\begin{abstract}
Given the massive campaign and information dissemination regarding sexually transmitted infections, the number of cases having HIV/AIDS and other sexually transmitted infections is still increasing at an alarming rate. It is observed by the researchers that individuals, especially teenagers engage in sexual practices without even considering its dangerous effects. This study aimed to determine why college students engage in sexual risky behaviors in spite of being educated with regards to sexually transmitted infections (STIs). A qualitative research design is utilized through case study approach among sexually active college students through snowball sampling. The data was then gathered through in-depth interview via guided questions. Ethical consideration was observed due to the sensitive, personal, and intimate nature of the interview. Result of the study showed that among the sexually active college students the feeling of pleasure was mainly the reason why they indulge in sexual intercourse, exposing themselves to risky sexual act. All of the study participants had multiple partners; had used contraceptive (condoms); had risky sexual history and had been knowledgeable about STIs. The case analysis revealed that the sexually active college students knew about the importance of prevention, but only one participant used contraceptive during sexual act. The participants admitted throwing 'caution-to-the-wind' due to perceived pleasure, feelings of love, curiosity and combined with alcohol and prohibited drugs in some of these encounters. There were three emerging theme that came out from the narratives namely; sexually active college students were susceptible due to inadequate knowledge regarding STI's; some had high knowledge but susceptible due to risky sexual behaviors, while there were participants who were sexually knowledgeable and careful. It is recommended that students should be required to participate in more interactive seminars or events that talks openly about their thoughts with regards to sex, sexually transmitted infections and awareness on the dangers of STIs through some risky sexual practices.
\end{abstract}

\section{Keywords: College student, Qualitative research, Sexual behavior, Thematic analysis}

\section{INTRODUCTION}

Sexual intercourse is defined as a physical contact between two individuals involving stimulation and penetration of genital organs. There are actually different types of sexual intercourse which includes anal, oral and vaginal sex. These sexual activities may be done by both heterosexual or homosexual people.

On the other hand, premarital sex is defined as the act of having sex before marriage. Premarital sex has been considered as a moral issue for a long period of time and this line of thinking is still evident in this generation. It is even a taboo in many cultures and is considered as a sin in many religious organizations.

The researchers have observed that people nowadays, especially teenagers often engage in sexual practices without even considering its dangers. Given that vaginal sex may lead to pregnancy and that all forms of sexual intercourse may somehow lead to sexually transmitted infections or diseases, it is alarming that the numbers are 
still increasing despite the prevalence of information disseminated concerning STIs through various education and technological information's in the internet.

Sexually transmitted diseases (STDs), or sexually transmitted infections (STIs), are generally acquired by sexual contact. The organisms that cause sexually transmitted diseases may pass from person-to-person through blood, semen, vaginal and other bodily fluids (Mayo Clinic Foundation for Medical Education and Research, 2017). There are actually different kinds of sexually transmitted infections and diseases; this includes chlamydia, hepatitis, human immunodeficiency virus / acquired immunodeficiency syndrome, syphilis, and etcetera. It is stated in National Unified Health Research Agenda (NUHRA) 2017-2022 that the $3^{\text {rd }}$ research priority are the holistic approach to health and wellness. It aims to produce evidence that is geared towards the application and recognition of traditional, sociocultural, and alternative approaches to health in addressing health system gaps. When it comes to providing nursing care it is important to apply holistic approach to all patients especially since a lot of combined factors may affect a person and a community's health. The circumstance of a person's lifestyle also affects negatively the person's health and well-being.

Another research priority from NUHRA, which is the research equity and health, aims to develop new solutions for the vulnerable populations and marginalized sectors of the society. By definition, vulnerability is the degree to which a population, individual or organization is unable to anticipate, cope with, resist and recover from the impacts of disasters (World Health Organization, 2002). In this case, it is the people infected with HIV/AIDS and other STIs. People infected with these diseases are often marginalized, discriminated producing a barrier to STI and HIV screening and control because of the stigma. So, while addressing these issues is one of the priorities of the study based to the National Unified Health Research Agenda 2017-2022 (PNHRS, 2017).

Premarital sex is rampant among young people, especially to college students and including those who are entering college. As observed, teenagers or students who enter college, sex has become normal, especially that there are already different online applications and social media in which people can connect; these applications include tinder, grinder, snapchat, and facebook. These are very popular among this generation.

College students engage into sex without even considering its effects in their health. They do not know how this will affect them but still, they engage in this matter. There are a lot of effects of engaging into unprotected sex, including teenage pregnancy, and sexually transmitted diseases or infections such as syphilis, HIV/AIDS, chlamydia, hepatitis, and etcetera which is due to sexually risky behaviors developed by these people because of their sexual practices and lack of knowledge on sexually transmitted infections or diseases. The several sexual practices that most people are engage include oral and anal sex, which are risk factors for STIs; not using of condom; sex with multiple partners; sex with the same sex; and inserting objects to the genitalia.

The researchers would like to find-out why college students, though aware and even educated about STIs still engage in risky sexual behaviors. Although there have been a numerous studies relating to this, but the researchers would like to dig deeper to those who are doing 'it' and relate it to their susceptibility of having the disease.

\section{METHODOLOGY}

This study utilized the qualitative research design using case study analysis in which it evaluated the college students' level of knowledge on sexually transmitted infections to describe their sexual practices and their possible susceptibility to having STIs.

The study was conducted in Mindanao State University-Iligan Institute of Technology for convenience and the heterogeneity of the student population which can represent the whole Mindanao. In this study, the researchers used the snowball method which is a recruitment technique in which research participants are asked to assist the researchers in identifying other potential subjects for data gathering. There were five (5) sexually active college students selected from different colleges in the Mindanao State University-Iligan Institute of Technology. Sexually active means they have been having sex within their stay in MSU-IIT, regardless of their personal relationship and regardless of the gender.

The researchers conducted an in-depth interview utilizing case study method to exhaust all possible 
themes from the interview transcripts which can then give a factual and substantial data in a way to support the study's intent.

The following were the actual guide question throughout the in-depth interview on each of the participants;

Preliminary Questions - Good morning, can you tell me about yourself?

1. Are you in a current relationship?

2. Are you in an intimate relationship with your partner/previous partner?

3. In what emotional situation, made you indulge on intimate acts?

4. Did you use any protection during those acts?

5. Do you know about sexually transmitted infections?

6. Since you have been intimate with your partner, do you think you are susceptible to STIs?

\section{Data Analysis}

For the five (5) case study, a narrative analysis was utilized to fully interpret the data gathered from the indepth interview that may showcase the college student's sexual behavior, knowledge and their susceptibility to having sexually transmitted infections. This approach typically focused on the lives of individuals as told through their own self-disclosure. The emphasis in such approach was on their story, typically both what and how the narration was done.
The purpose of narrative analysis was to identify the kinds of stories told about the research phenomenon and the kind of story representing the phenomenon in culture and society. Narrative analysis may focus, for example, on text, media text, picture, film, music and an environment, which act as a story or have a story-like structure.

During the interview, the researchers prioritized the privacy, confidentiality and anonymity of the participant. Prior to the study, the researchers sought the approval for the study via the College Research Ethics Committee and Institute Research Ethics of Mindanao State University-Iligan Institute of Technology (MSUIIT). The researchers then obtained the full consent from the intended participants. Protection for the privacy of the participants as well as the adequate level of confidentiality of the research data was ensured. Honesty and transparency in any type of communication in relation with the research was maintained. The respondents were assured that they can withdraw at any given time, if they felt uncomfortable with the said interview. The institute guidance counselor was made available to give debriefing if needed.

\section{RESULTS}

Table 1 showed the following testimonies of college students and the candid confession of their sexual lives and subsequent experiences which answered the author's query on the matter of their sexual knowledge, behavior and sexually transmitted infections (STIs).

Table 1: Cross case matrix of the college students' demographic profile, their sexual knowledge, behaviors that can impact their susceptibility to STI's and Themes

\begin{tabular}{|c|c|c|c|c|c|}
\hline & $\begin{array}{l}\text { Case 1. } \\
\text { College Student not in } \\
\text { current relationship, } \\
\text { with low knowledge on } \\
\text { STIs, not sexually } \\
\text { active and does not use } \\
\text { precautions during sex. }\end{array}$ & $\begin{array}{l}\text { Case } 2 \text {. } \\
\text { College Student not in a } \\
\text { relationship, with low } \\
\text { knowledge on STIs, } \\
\text { sexually active and does } \\
\text { not use precautions } \\
\text { during sex. }\end{array}$ & $\begin{array}{l}\text { Case } 3 \text {. } \\
\text { College student in a } \\
\text { current relationship, } \\
\text { with high knowledge of } \\
\text { STIs, sexually active } \\
\text { but does not us e } \\
\text { precautions during sex. }\end{array}$ & $\begin{array}{l}\text { Case } 4 \text {. } \\
\text { College student not in a } \\
\text { current relationship, } \\
\text { with high knowledge on } \\
\text { STIs, sexually active } \\
\text { but uses protection } \\
\text { during sex. }\end{array}$ & $\begin{array}{l}\text { Case } 5 \text {. } \\
\text { College student in a } \\
\text { current relationship, } \\
\text { with multiple partner, } \\
\text { has high knowledge on } \\
\text { STIs, sexually active } \\
\text { but does not use any } \\
\text { protection during sex }\end{array}$ \\
\hline Age & 20 & 20 & 21 & 20 & 21 \\
\hline Sex & Male & Male & Female & Male & Male \\
\hline $\begin{array}{l}\text { Sexual } \\
\text { Preference }\end{array}$ & Straight & Straight & Straight & Straight & Straight \\
\hline
\end{tabular}




\begin{tabular}{|c|c|c|c|c|c|}
\hline $\begin{array}{l}\text { Sexual history } \\
\text { of the respondents }\end{array}$ & $6-8$ & $5-6$ & 2 & 2 & 12 \\
\hline $\begin{array}{l}\text { Current relationship? } \\
\text { no.-of sex partners }\end{array}$ & $\begin{array}{l}\text { No } \\
6-8\end{array}$ & $\begin{array}{l}\text { No } \\
5-6\end{array}$ & $\begin{array}{l}\text { Yes } \\
2\end{array}$ & $\begin{array}{l}\text { No } \\
2\end{array}$ & $\begin{array}{r}\text { Yes } \\
12\end{array}$ \\
\hline $\begin{array}{l}\text { Reason for } \\
\text { indulging in intimate acts }\end{array}$ & Pleasure & Curiosity \& pleasure & Love \& pleasure & Pleasure & $\begin{array}{c}\text { Spur of the moment, } \\
\text { Passionate encounters } \\
\text { pleasure }\end{array}$ \\
\hline \multicolumn{6}{|l|}{$\begin{array}{l}\text { Level of Knowledge } \\
\text { regarding STIs }\end{array}$} \\
\hline -Use protection? & Used only once & Used only once & Used only once & Yes (regular) & Used only twice \\
\hline -Knowledg e of STIS & -Only HIV-AIDS & $\begin{array}{l}\text {-only gonorrhea and } \\
\text { HIV-AIDS }\end{array}$ & -knows all STIs & -knows all about STIs & -Knows all about STIs \\
\hline $\begin{array}{l}\text { Risky sexual practices or } \\
\text { acts committed by these } \\
\text { College students }\end{array}$ & $\begin{array}{l}\quad 2 \text { sexual } \\
\text { partners met at the bar; } \\
\text { one-night stand; friends } \\
\text { with benefits; genital \& } \\
\text { oral sex; use of alcohol } \\
\text { and drugs (once) }\end{array}$ & $\begin{array}{l}\quad \text { One-night } \\
\text { stand met at the bar; } \\
\text { sex while in the } \\
\text { influence of alcohol } \\
(8 \mathrm{x})\end{array}$ & $\begin{array}{l}\quad \text { Had sex in } \\
\text { the influence of } \\
\text { alcohol; had sex } \\
\text { outside a relationship; } \\
\text { indulge in genital and } \\
\text { oral sex }\end{array}$ & $\begin{array}{l}\qquad \text { Had } \\
\text { relationship outside } \\
\text { relationship (once)f; } \\
\text { indulge in genital and } \\
\text { oral sex }\end{array}$ & $\begin{array}{l}\quad \text { Had one- } \\
\text { night stand; } 2 \text { hook-ups; } \\
\text { friend-with-benefits; } \\
\text { had indulge in genital, } \\
\text { oral and anal sex. }\end{array}$ \\
\hline $\begin{array}{l}\text { Use of Precaution when } \\
\text { indulging in Sex }\end{array}$ & $\begin{array}{l}\text { Used } \\
\text { condom during his } \\
\text { early intimate acts }\end{array}$ & $\begin{array}{c}\text { Used } \\
\text { condom once }\end{array}$ & $\begin{array}{c}\text { Used } \\
\text { condom once }\end{array}$ & $\begin{array}{c}\text { Used } \\
\text { condom regularly }\end{array}$ & $\begin{array}{c}\text { Used } \\
\text { condom only twice. }\end{array}$ \\
\hline Susceptible to STIs? & Highly at Risk & Highly at Risk & Highly at Risk & Low Risk & Highly at Risk \\
\hline Emergent Sub-themes & $\begin{array}{l}\quad \text { Sexually } \\
\text { active college student } \\
\text { but highly at risk due } \\
\text { to low knowledge and } \\
\text { susceptible due to risky } \\
\text { behaviors. } \\
\text { Susceptible due to } \\
\text { inadequate } \\
\text { knowledge to STI's }\end{array}$ & $\begin{array}{l}\quad \text { Sexually } \\
\text { active students may } \\
\text { have adequate } \\
\text { knowledge on STIs, } \\
\text { but are still susceptible } \\
\text { due to their risky } \\
\text { sexual behaviors. } \\
\text { Adequate Knowledge } \\
\text { but susceptible due to } \\
\text { risky sexual } \\
\text { behaviors }\end{array}$ & \begin{tabular}{l}
\multicolumn{1}{c}{ Sexually } \\
active college student \\
with high knowledge, \\
uses precaution during \\
sex therefore, low risk \\
for STIs. \\
Sexually Responsible \\
and knowledgeable
\end{tabular} & & \\
\hline
\end{tabular}

\section{Participant A}

Participant A is a male, 20-year-old, fourth-year college student and is not in any current relationship. He considered himself to be sexually straight. However, he had three past relationships. He started engaging in intimate acts, such as holding hands, kissing, hugging, and having sex when he was in high school, of which according to him is because of pleasure or simple sexual gratification. Participant A said that he probably had a total of six to eight sexual partners. Recently, he had two sexual partners that he just met at the bar. He claimed that in a month, he would probably be engaged in sexual intercourse at least once or twice.

Participant A had tried having hook-ups, one-night stand, and friends-with-benefits for a total of six encounters. However, he admitted that he does not engage in sexual intercourse with other partner, if he is in a serious relationship. Although Participant A is sexually active, he has used condom several times when he was experimenting with sex. But in the long run, he stopped using condom because he felt uncomfortable and opted for the withdrawal method. Sometimes he considered asking his sex partner their sexual history. However, he did not ask them if they had 
used condom with those partners because there is a possibility that they will only lie or not tell the truth. Participant A had experienced having a sexual contact while under the influence of alcohol and drugs (marijuana). Before engaging in sex, he practiced good hygiene by taking a bath. But there are also times that he cannot take a bath, especially if he was drunk or in the height of passion.

Participant A stated that he had learned about sexually transmitted infections but only knew HIV/AIDS since it is popular among the STIs. According to him, STIs are group of infections and that HIV/AIDS are not the same. He added that condoms cannot prevent HIV/AIDS and that sexually transmitted infections can be transmitted through sexual contact. However, he answered that HIV acquired from mosquito bites and that AIDS can be transmitted through sex. Participant A believes that he is at risk for having STIs because he has had multiple partners but is confident that his partners are clean.

\section{Participant B}

Participant B is a male, 20-year-old, a third-year college student and is heterosexual. He is currently not in a relationship, however, he had three past girlfriends. Participant B started engaging in intimate acts when he was seventeen years old mostly because of curiosity and sexual pleasure. Throughout his life, Participant B claimed to have had five to six sexual partners. Recently, he had one sexual partner and claimed to have sex five times a month.

Participant B reported to have experienced eight one-night stands with those he met at the bar. However, he did engage in sexual intercourse with a different partner while he was in a relationship. Although Participant B is sexually active, he had only tried using condom once during his first sexual intercourse. He also considers asking his partners regarding their sexual history before having sex with them for safety. Participant B have also experienced having sex while under the influence of alcohol for eight times. He considered taking a bath before and after engaging in any sexual contact.

Participant B claimed to have heard about sexually transmitted infections from a friend in which experienced having discharges or pus in his genital after having sex with a girl. Participant B claimed to have heard and knew only about HIV/AIDS since those were the only common types of STIs. However, Participant B cannot really differentiate HIV/AIDS, but claims that they are not in the same category and that STIs can only be transmitted through genital and oral sexual contact and can be prevented through using condoms. Since Participant B is sexually active, he knows that he is at risk of having STIs because of his experiences.

\section{Participant C}

Participant C is a female, 21-year old, and a fourthyear college student. She considers herself a straight woman and is in a current relationship for the past four months during the interview. She had a total of four relationships where the last two were considered to be serious ones. So far, she had two sexual partners including her current partner. Participant $\mathrm{C}$ started engaging in sexual intercourse at the age of nineteen years and claimed to engage in sexual intercourse with her partner at least twice a month.

Participant $\mathrm{C}$ does not use any protections except condoms, however she was able to use it once while engaging sexual intercourse due to the discomfort. Participant $\mathrm{C}$ claimed to have engaged in sexual intercourse under the influence of alcohol. She was also engaged in sexual intercourse outside relationship once, where she just met the guy. Before having sex with her partner, Participant C asks for her partner's sexual history such as, last time was her partner had sex, how many partners, and whether her partner used condoms for protection.

Participant $\mathrm{C}$ claimed to have heard about sexually transmitted infections and is aware of how rampant it is especially in the city. She named HIV and AIDS as one of the sexually transmitted infections and she also knows that sex is one of the modes of transmission of STIs. She differentiated HIV as a serious case but there is already medication that could help control the disease, whereas AIDS is the worst case scenario after HIV. Since Participant C is sexually active, she thinks that she is at risk of having sexually transmitted infections because of having sex without any protection, however, she is confident that she will not be at risk considering that she is loyal to her current partner.

\section{Participant D}

Participant D is a male, 20-year-old, and a fourth- 
year college student. He considers himself straight, but is not in a current relationship. He has been in a relationship once which lasted for more two years. He started engaging in sexual intercourse at the age of seventeen and was intimate with his partner. Throughout his life, he had two sexual partners. He engaged in sexual intercourse with his partner almost every day every time they meet.

Participant D used condoms multiple times for protection whenever engaging in sexual intercourse with his partner. He had also engaged in sexual intercourse outside his relationship once. Being sexually active, he tried genital and oral sexual contact. Before having sex with his girlfriend, he asks about her previous relationship and sexual intimacy with boyfriends. However, when he had sex with the other girls other that his girlfriend, he admittedly that he did not ask the other girl's sexual history.

Participant D claimed to have heard about sexually transmitted infections and has seen seminars regarding HIV/AIDS. He was clear of the mode of transmission of STIs as mentioned intercourse. Among the different types of STIs he named gonorrhea and candidiasis. He also believes that condoms can prevent STIs. He aware of HIV virus and AIDS as the severe case after HIV. Since Participant D is sexually active, he claims that he is not at risk of having STIs considering that he only had two partners in his lifetime and tries to practice safe-sex by using condoms.

\section{Participant E}

Participant E is a male, 21-year-old, fourth-year college student who considers himself straight and presently in a relationship for six months. He admitted to have a total of twelve past relationships which lasted for several months to a year. Participant $E$ has been intimate with his previous and current partners but was only intimate with only 6 of them. He started engaging in sex when he was in his first-year of college considering spur-of-the-moment and passionate encounter. He has had four sexual partners for the past 2-3 years. With his current partner, he gets engaged in sexual intercourse for only once a month.

Since Participant E is sexually active, he answered that he had only used it twice because he does not like it. He also admitted that he had experienced having sex with a girl with whom he was not in a relationship. In addition, he had experienced having 2 hookups, onenight stand and a friend-with-benefits. He had also experienced having sex with different partners, while he was in a current relationship. He does not use condom still and only considered asking his sexual partners regarding their sexual history before engaging in sex, but he does not include those partners that he is not in a relationship with. He had also experienced having sex while under the influence of alcohol. He shared that he often takes a bath before engaging in sexual intercourse, but sometimes was not able to do this also.

Participant E have attended an HIV awareness seminar once and claimed that STIs can only be transmitted through blood and sexual intercourse. He mentioned several types of STIs that he knew of such as gonorrhea, syphilis and HIV. He also thinks that having multiple partners can lead to STIs and that condoms does not guarantee a hundred percent assurance to prevent one from STIs. He also claimed that, HIV and AIDS are not the same, in which he stated that AIDS is the next step or the worst-case scenario of HIV. His mother encouraged him for HIV testing and considered to do it but have not done it yet. He also thinks that he is at a risk of having STIs since he is sexually active and had multiple sex partners and that he does not use any protection (condom).

\section{DISCUSSION}

The narrative of five participants tells a story about their sexual experiences. The in-depth interview provided a profound sexual history, experiences and behaviors of the sexually active college students.

Participants A, B, C, D, and E whose ages range from 20-21 years were all straight and are all sexually active college students. Four were male (Participants A, $\mathrm{B}, \mathrm{D}$ and $\mathrm{E}$ ) and only one female (Participant C). Three of them are not currently in a relationship (Participants $\mathrm{A}, \mathrm{B}$, and D) while two are currently in a relationship for about 5 to 6 months (Participants $\mathrm{C}$ and $\mathrm{E}$ ). All the participant had multiple partner throughout their lives in which all of them had similar reasons indulging in intimate acts, mostly because of sexual pleasure while other participants believed that it was love, curiosity, and spur of the moment/passionate encounters. The table also showed that participants A, B, C and E had only used condom once, while participant D used 
condom regularly. This is similar to the result of a study by Caico (2014) about sexually risky behavior among college students due to their sexual risk-taking behavior and the knowledge level wherein, the findings revealed that college students tend to have sexual intercourse with two to five individuals, and had unprotected vaginal intercourse without using condoms or using it occasionally (Caico, 2014).

When it comes to the knowledge of the participants on sexually transmitted infections, it showed that participants C, D and E knew more about STIs, while participant A knew only about HIV/AIDS, and participant B only knew about HIV/AIDS and gonorrhea. All of them had experienced having sexual encounters in such as hookups, one-night stand and friends with benefits with strangers. This risky sexual behavior was also like the result of a study in which a consistent number of students are exposed to risk factors for Sexually Transmitted Disease (STD) like alcohol and use of recreational drug, promiscuity and improper condom use (Drago et al., 2017). Furthermore, it was found out that Participants A, B, C, and $\mathrm{D}$ preferred having genital and oral sex, while participant $\mathrm{E}$ includes anal sex without using any protection. Most of the students were aware of different sexual risks, however the result indicated that still, several students found it difficult to ask their partner to use condom (Faimau et al., 2016). As table 1, indicates that participants $\mathrm{A}, \mathrm{B}, \mathrm{C}$, and $\mathrm{E}$ were highly at risk for STIs while participant $\mathrm{D}$ is considered to be comparatively at lower risk due to his knowledge and tried to practice safe sex.

From the collected data narratives, the following themes were formulated:

Theme 1: Sexually active students are susceptible to STIs due to poor knowledge on STIs.

The respondents were asked about what they knew about STIs and impart their knowledge with the researchers. Asking them on whether they use condoms for protection while engaging in sexual intercourse, majority of them answered once or twice. Students having poor knowledge on STIs only make themselves susceptible to STIs for they engage in sexual activities without taking into the consideration on the risks that they are exposed to.

When asked about the types of STIs, Participant low knowledge about STIs, made them susceptible to the infections due to blatant disregard of their sexual behaviors which may result to their risk in having STIs. In a study by Caetano et al., (2010) about the sexual behavior and knowledge about sexually transmitted infections (STIs) among undergraduate students in Sao Paulo, Brazil, it was found that students engaged in high-risk sexual behavior with multiple partners as they use condoms inconsistently due to poor knowledge on the acquisition and modes of sexual and vertical transmission of HIV.

Theme 2: Sexually active students may have adequate knowledge on STIs, but are still susceptible due to their risky sexual behaviors.

Having adequate knowledge on STIs does not guarantee that one will not be at risk of having it. From the data that the researchers have gathered and analyzed, it clearly showed that despite their ample knowledge on STIs, the respondents disregarded their knowledge because they were driven by their emotions and feelings. Emotions and feelings such as spur of the moment, passionate encounter, love, affection, pleasure and curiosity are several reasons, that these college students ignore when having sex. It made them vulnerable or at risk because of the said intrinsic motivation that basic precaution and logic must be exchanged with sexual enjoyment or fun (Houck et al., 2014). This explains why even sexually active college students, despite having adequate knowledge on STIs are still susceptible. It is further shown in the table that although participants are knowledgeable on certain STIs, but they are still susceptible for STIs since they do not apply this knowledge before engaging in sexual intercourse. This result finding were similar to a study done about the assessment of knowledge on sexually transmitted infections and sexual risk behavior in Bhutan, wherein it was revealed that though they were knowledgeable about STIs and their complications, but this did not increase or decrease their risky sexual behaviors (Norbu, Mukhia \& Tshokey, 2013).

Theme 3: Sexually active students who are at low risk due to being sexually responsible and knowledgeable.

Some might say but having knowledge alone will not help much if a person does not know how to make use of it. Out of the five cases shown in Table 1, only one participant had knowledge on STIs, and was the only one who observed precautionary measures when engaging in sexual intercourse. Sexually active college 
students who have the knowledge on STIs is of great advantage but applying caution while sexual act would really lessen the tendency of them being infected with STIs. Sexually active college students will be at risk of getting the infections in the future due to negligence on matters related to STIs and lack of precautionary measures.

The result of the study showed that most of the respondents had experienced having sex with a person that they are not in a relationship with. The respondents also revealed that many of them do not use condom, and had used condom only during their first few encounters. So they demonstrate risky behaviors among which were; having multiple partners, not using a protection (condom), engaged in sex at an early age (between fifteen to twenty-four) and having sex while under the influence of alcohol and drugs are considered to be hazardous.

During the in-depth interview, the researchers had also assessed the level of knowledge of the respondents in which it showed that they have adequate knowledge regarding sexually transmitted infections. Mostly, the respondents only knew the common STIs such as HIV/AIDS, while some of them were not able to correctly differentiate the two. Most of the respondents also knew how STIs were transmitted and how they can be prevented.

Based from the data gathered, most of the respondents had adequate knowledge on sexually transmitted infections, however, they still do not apply this knowledge when engaging in any sexual activities merely because of their feelings such as change spur to 'heat of the moment' passionate encounters, love, pleasure and affection towards the person. In addition, these students prefer not to use condom while engaging in sexual intercourse since they were not used to it and it makes them uncomfortable. Thus, increasing their susceptibility to having STIs.

After gathering and interpreting the data, the researchers concluded that there is blatant disregard in the part of the respondents in spite of their knowledge and information regarding STIs that they still preferred to have unprotected sexual intercourse. This was corroborated in a study made by Subbarao \& Akhilesh (2017) on knowledge and attitude about sexually transmitted infections other than HIV among college students. It was found that college students engaged in sexual activity may have or may not have adequate knowledge on STI that could guarantee safe sex or nontransmission of STI's.

The researchers believed that there is a possibility that a greater portion of the population might be practicing the same sexual behaviors for the same reason i.e. for pleasure despite of the knowledge and the information they have on STIs which may lead them into acquiring of STI's.

\section{CONCLUSION}

The researchers recommend that college students must participate in interactive seminars or events that talks about sexually transmitted infections for them to realize the danger they are risking themselves to. Moreover, they must undergo voluntary and confidential STI screening and testing. This should be made accessible in the university clinic every academic year. It is also recommended that sexually active students should be encouraged to attend school-sponsored seminars and events regarding STIs in order to minimize their risky sexual practices and behaviors. And lastly, these sexually active students should also be guided psychologically and emotionally regarding their wrong perception and reasons in indulging to sex, thus preventing experimentation and exposing themselves to a wrong kind of relationships.

\section{REFERENCES}

Caetano, M.E., Linhares, I.M., Pinotti, J.A., Maggio da Fonseca, A., Wojitani, M.D. \& Giraldo, P.C. (2010). Sexual behavior and knowledge of sexually transmitted infections among university students in Sao Paulo, Brazil. International Journal of Gynecology \& Obstetrics, 110(1), pp 43-46.

Caico, C. (2014) Sexually Risky Behavior in College-Aged Students. Open Journal of Preventive Medicine, 4, pp 354-364. 
Drago, F., Ciccarese, G., Zangrillo, F., Gasparini, G., Cogorno, L., Riva, S., Javor, S., Cozzani, E., Broccolo, F., Esposito, S. \& Parodi, A. (2016). A survey of current knowledge on Sexually Transmitted Diseases and Sexual Behaviour in Italian Adolescents. International Journal of Environmental Research and Public Health, 13(4): 422.

Faimau, G., Maunganidze, L., Tapera, R., Mosomane, L.C.K., Apau, S. \& Halsall, J. (2016). Knowledge of HIV/AIDS, attitudes towards sexual risk behaviour and perceived behavioural control among college students in Botswana. Cogent Social Sciences, 2(1), pages 16.

Houck, C., Swenson, R., Donenberg, G., Papino, A., Emerson, E. \& Brown, L.K. (2014). Adolescents' emotions prior to sexual activity and associations with sexual risk factors. AIDS and Behavior, 18(8), pp 1615-1623.

Mayo Clinic Staff, Mayo Clinic Foundation for Medical Education and Research (2017). Sexually Transmitted Diseases. Retrieved from: https://www.mayoclinic.org/diseases-conditions/sexually-transmitted-diseasesstds/symptoms-causes/syc-20351240

Norbu, K., Mukhia, S. \& Tshokey (2013). Assessment of knowledge on sexually transmitted infections and sexual risk behaviour in two rural districts of Bhutan. BMC Public Health, 13(1): 1142.

Philippine National Health Research System (PNHRS) (2017). National Unified Health Research Agenda 20172022. Retrieved from: https://www.doh.gov.ph/sites/default/files/publications/NUHRA.pdf

Subbarao, N.T. \& Akhilesh, A. (2017). Knowledge and attitude about sexually transmitted infections other than HIV among college students. Indian Journal of Sexually Transmitted Diseases and AIDS, 38(1), pp 10-14.

World Health Organization (2002). Environmental Health in emergencies. Vulnerable groups. Retrieved from: https://www.who.int/environmental_health_emergencies/vulnerable_groups/en/?fbclid=IwAR3hiwKC2FQ xsnrwe6gg3di4rwbVpV76Pxa_eYebvc0Rb8̄OkKzTHuXgCSw8 